\title{
V19 - INFLUÊNCIA DA TAXA DE CONGELAMENTO NA VELOCIDADE DE SUBLIMAÇÃO DURANTE O PROCESSO DE LIOFILIZAÇÃO
}

$\underline{\text { Sérgio Luiz de Lima Assumpção }}{ }^{1}$, Celso de Farias Crespo.

1. Escola Politécnica de Saúde Joaquim Venâncio, Bio-Manguinhos, Fiocruz, Rio de Janeiro, Brasil.

Objetivo: Correlacionar a taxa de congelamento de uma formulação à velocidade de sublimação alcançada durante o processo de liofilização.

Metodologia: Esse trabalho consistiu em produzir dois lotes liofilizados de formulação à base de sacarose, onde os parâmetros dos ciclos de liofilização foram fixados, ou seja, as programações de temperatura e pressão dos dois ciclos utilizados eram idênticas à exceção das taxas de congelamento que, no primeiro ciclo foi de $-0,22^{\circ} \mathrm{C} / \mathrm{min}$ e no segundo $-1,77^{\circ} \mathrm{C} / \mathrm{min}$. Nos dois experimentos, durante a sublimação do produto na câmara do liofilizador, foi medida a velocidade de redução de massa do produto no frasco. Esse método consiste em coletar amostras cujas massas do volume envasado tenham sido registras logo após o envase. A coleta de amostras é feita com auxílio do "braço" do liofilizador piloto. Os frascos que foram previamente identificados e pesados são pesados novamente após o tempo de exposição à secagem. Com os valores de massa inicial, massa final e intervalo de tempo sob sublimação foi feito o tratamento computacional utilizando o software Origin 7.0. A metodologia consiste em montar curvas de redução de massa em relação ao tempo sob a condição de programação do ciclo de liofilização.

Resultado: A taxa de congelamento programada no ciclo apresenta um alto impacto na velocidade de sublimação da formulação à base de sacarose que utilizamos. Com as taxas de congelamento utilizadas verificou-se que, para taxa de congelamento mais lenta, $0,22^{\circ} \mathrm{C} / \mathrm{min}$, tem-se uma sublimação mais rápida que a sublimação alcançada no outro experimento, onde a formulação foi congelada à taxa de $-1,77^{\circ} \mathrm{C} / \mathrm{min}$. Assim, verificouse experimentalmente, conforme se encontra na literatura, que para um congelamento mais lento, obtem-se uma sublimação mais rápida. 
Conclusão: A taxa de congelamento é um parâmetro importante a ser considerado quando da elaboração de um ciclo de liofilização, pois está relacionada fortemente com o tempo total do processo, com o tempo total do ciclo. Além disso, sabe-se da literatura que o tipo de cristal formado durante o congelamento tem um importante impacto nos resultados biológicos. Devido a efeitos desnaturastes das baixas temperaturas, e do tamanho dos cristais formados, pode-se observar danos a membrana plasmática e ao citoplasma celular. Neste trabalho, não foram realizados estudos biológicos para avaliar ganhos e perdas, por exemplo, em parâmetros como a potência. Entretanto, a utilização de uma taxa de congelamento adequada à formulação a ser liofilizada, sobretudo na produção em escala comercial, deve considerar a condição que otimize o tempo do processo, preservando sobretudo os requisitos da qualidade de produto final estabelecidos por agências reguladoras. 